\title{
Kajian Tatanan Bentuk Arsitektur Simbolis pada Pengembangan Museum Trinil di Kabupaten Ngawi
}

\author{
Rizal Denarian Sudibyo ${ }^{1}$, Ika Ratniarsih ${ }^{2}$, Sigit Hadi Laksono ${ }^{3}$ \\ 1,2,3Jurusan Arsitektur, Fakultas Teknik Sipil dan Perencanaan, Institut Teknologi Adhi Tama Surabaya \\ Email: 1 rizaldena11@gmail.com
}

\begin{abstract}
Abstrak. Ngawi Regency is a place of ancient sites whose existence is less known by the public. Due to the lack of supporting facilities for the Trinil Museum which holds a lot of ancient history. The development at the Trinil Museum is needed to make the museum run optimally and become a big icon for Ngawi Regency. The method used to compile this report is the descriptive method in which there are literary case studies and field case studies by comparing and making references to the development plan. The location of the Trinil Museum which will be developed is in Kawu Village, Kec. Kedunggalar, Ngawi Regency, East Java. The land area on the site reaches $\pm 15,000 \mathrm{~m} 2$ (1.5 hectares), borders with Bengawan Solo, forest and community settlements in Kawu Village. Facilities that will be added to the design object are Main Facilities: Exhibition and Education Building Facilities, Entertainment Facilities, Archeological Facilities, Supporting Facilities: Management Building Facilities, Restaurant and Cafe Facilities, Meeting Facilities, Lodging Facilities, Outbound Facilities, Service Facilities (Toilets, EEC, Warehouse, Loading Dock, Drop Off). The theme used for this design is symbolic, symbolic here uses a disguised metaphor where the manifestation is disguised so that people who see the object think and have their own point of view, where the process is by adapting / integrating with the surrounding environment and taking different forms. characterizes the Ngawi area with an emphasis on ancient accents. The application of the theme to the land arrangement is a form of circulation such as bones, the application of the theme to the shape is on the roof using the roof found in the area with the addition of ancient shapes and textures such as stones and bones, the application of the theme to the space is the emphasis of stone accents and the color of stone and wood. The benefit of designing this object is to make the Trinil Museum run even more optimally, to provide a forum for research and people who want to study archeology and to make it a great icon for Ngawi Regency.
\end{abstract}

Keywords: Museum, Ngawi, Development, Symbolic, Trinil

\begin{abstract}
Abstrak. Kabupaten Ngawi adalah tempat situs purba yang keberadaannya kurang diketahui oleh khalayak ramai. Dikarenakan kurangnya fasilitas penunjang terhadap Museum Trinil yang menyimpan banyak ilmu sejarah purbakala. Pengembangan di Museum Trinil diperlukan guna menjadikan museum tersebut berjalan secara maksimal dan menjadi suatu ikon yang besar untuk Kabupaten Ngawi. Metode yang di gunakan untuk menyusun laporan ini adalah Metode Deskriptif dimana dalam metode tersebut terdapat Studi Kasus Literatur dan Studi Kasus Lapangan dengan membandingkan dan menjadikan referensi untuk rencana pengembangan tersebut. Lokasi Museum Trinil yang akan dikembangkan berada di Desa Kawu, Kec. Kedunggalar, Kabupaten Ngawi, Jawa Timur. Luas Lahan pada tapak mencapai $\pm 15.000 \mathrm{~m} 2$ (1,5 Hektar), Berbatasan dengan Bengawan Solo, Hutan dan pemukiman warga Desa Kawu. Fasilitas yang akan ditambahkan pada objek rancangan tersebut yaitu Fasilitas Utama : Fasilitas Gedung Pameran dan Edukasi, Fasilitas Hiburan, Fasilitas Arkeologi, Fasilitas Penunjang : Fasilitas Gedung Pengelola, Fasilitas Restoran dan Kafe, Fasilitas Pertemuan, Fasilitas Penginapan, Fasilitas Outbond, Fasilitas Servis (Toilet, MEE,Gudang,Loading Dock, Drop Off). Tema yang digunakan untuk rancangan ini adalah simbolis, simbolis disini menggunakan metafora tersamar dimana perwujudannya dengan cara disamarkan agar orang yang melihat obyek tersebut berfikir dan memiliki sudut pandang masing-masing, dimana prosesnya dengan cara adapatasi/ menyatu dengan lingkungan sekitar dan mengambil bentuk-bentuk yang menjadi ciri khas daerah Ngawi dengan penekanan aksen purbakala. Penerapan tema pada tatanana lahan adalah bentuk sirkulasi seperti tulang, penerapan tema pada bentuk adalah pada atap menggunakan atap yang terdapat pada daerah tersebut dengan ditambah bentuk dan tekstur purba seperti bebatuan dan tulang,
\end{abstract}


penerapan tema pada ruang adalah penekanan aksen bebatuan dan warna batu dan kayu. Manfaat dari perancangan objek ini yaitu agar Museum Trinil berjalan lebih maksimal lagi, memberikan wadah untuk penelitian dan orang yang ingin belajar ilmu kepurbaan dan menjadikan suatu ikon yang besar untuk Kabupaten Ngawi.

Kata kunci: Museum, Ngawi, Pengembangan, Simbolis, Trinil

\section{Pendahuluan}

Pada museum Trinil banyak fasilitas yang kurang memadai dan lahan kosong yang seharusnya dapat dikembangkan agar museum ini dapat berfungsi secara maksimal melayani pengunjung. Beberapa fasilitas kondisinya terlihat tidak terawat, kurang menarik perhatian pengunjung dan ada beberapa fasilitas yang sudah tidak difungsikan, seperti guest house. Terdapat beberapa fasilitas yang kebutuhannya tidak tercukupi, seperti toilet.

Pada museum Trinil bentuk bangunan mengambil dari ciri khas yang ada di Kabupaten Ngawi, seperti bentuk bangunan joglo, limasan dan gapura yang merupakan bentuk bangunan / rumah adat daerah setempat. Dan bentuk - bentuk benda peninggalan sejarah yang terdapat pada daerah tersebut, seperti tanduk gajah purba.

Dengan melihat data-data di atas, Perencanaan dan Perancangan Pengembangan Komplek Museum Purbakala Trinil di Kabupaten Ngawi sangat diperlukan. Agar kegiatan di museum tersebut lebih banyak dan berjalan maksimal dalam pelayanan pengunjung. Pengembangan ikonik Kabupaten Ngawi yang diharapkan lebih besar citranya, dikenal oleh wisatawan dalam dan luar negeri dan menjadi tambahan pendapatan daerah yang nantinya akan mengangkat ekonomi mikro di Kabupaten Ngawi.

Perencanaan Dan Perancangan Pengembangan Komplek Museum Purbakala Trinil di Kabupaten Ngawi menerapkan tema Arsitektur Simbolis. Pemilihan tema di sini berdasarkan kesamaan sifat museum itu sendiri yakni mengangkat ciri khas di daerah Ngawi. Sama dengan sifat simbolis, nantinya hasil karya arsitektur ini akan mengangkat ciri khas di daerah Ngawi. Beberapa ciri khas di daerah Ngawi yang nantinya akan diangkat untuk tema museum disini antara lain adalah bentuk bangunan yang ada di daerah tersebut serta simbol-simbol bangunan daerah setempat seperti rumah adat daerah tersebut, gapura dan bentuk-bentuk bangunan sejarah seperti candi, bangunan kerajaan-kerajaan kuno, bentuk-bentuk bangunan Belanda, bentuk-bentuk zaman batu dsb.

\section{Tinjauan Pustaka}

Metafora adalah sebuah konsep dalam desain arsitektur, terutama di era arsitektur kekinian dan banyak diaplikasikan pada bangunan publik. Ditinjau dari segi bahasa, metafora berasal dari Bahasa Latin, tersusun dari kata "metha" yang berarti "setelah/ melewati" dan "Pherin" yang berarti "membawa". Sedangkan dari segi etimologi, metafora berarti perpindahan suatu makna, atau bisa juga disebut kiasan (Prihutama \& Ashadi, 2020). Dalam dunia arsitektural, metafora diartikan sebagai sebuah isyarat yang yang dimiliki oleh suatu obyek dan diterima oleh indra seseorang dan dapat dibandingkan dengan objek yang lain dan dilanjutkan pada sebuah bangunan sebagai sesuatu objek lain yang serupa dengannya, melalui suatu hubungan paralel secara abstrak (Asy'ari, Nirwansyah, 2013 dan Harmanta, Ashadi, Luqmanul Hakim, 2019). Duerk dalam Arrumaisa \& Suryawan (2014) menyebutkan perilaku metafora sebagai: (1) Usaha untuk memindah-rujukan dari satu subjek (konsep) atau objek ke subjek yang lain; (2) Usaha untuk melihat sebuah subjek (konsep) atau objek) sebagaimana jika subjek tadi berupa subjek lain; dan (3) Pemindahan pusat perhatian kita dari suatu hal (area of concentration or one inquiry) ke hal yang lain.

Dari Jenis Simbol Menurut Anthony C. Antoniades Ada tiga kategori metafora : (1) Intangible Metaphors (metafora yang tidak diraba/ tersamar) yang termasuk dalam kategori ini misalnya suatu konsep, sebuah ide, kondisi manusia atau kualitas-kualitas khusus (individual, simbol, naturalistis, komunitas, tradisi dan budaya); (2) Tangible Metaphors (metafora yang dapat diraba/langsung) Dapat dirasakan dari suatu karakter visual atau material; dan (3) Combined Metaphors (penggabungan antara keduanya/campuran) Secara konsep dan visual saling mengisi sebagai unsur-unsur awal dan visualisasi sebagai pernyataan untuk mendapatkan kebaikan kualitas dan dasar. (Shauma Eska Pranata et al., 2017)

Jadi, Arsitektur Metafora, pada umumnya memiliki karakter layaknya gaya bahasa metafora yaitu perbandingan dan perumpamaan. Karakter tersebut diterjemahkan dalam visual meliputi hal-hal 
sebagai berikut ini: (1) Berusaha untuk mentransfer suatu keterangan (maksud) dari suatu subjek ke subjek lain; (2) Berusaha untuk melihat suatu subjek seakan-akan subjek tersebut adalah sesuatu hal yang lain; dan (3) Mengganti fokus penelitian atau area konsentrasi penyelidikan lainnya, dengan harapan jika membandingkannya dengan cara pandang yang lebih luas, maka akan dapat menjelaskan subjek tersebut dengan cara yang berbeda (baru). Prinsip Simbol Tersamar: Metafora berangkat dari sesuatu yang abstrak dan tak terlihat (tak berbentuk). Penggunaan simbol yang disematkan menggunakan aspek seperti konsep, ide, hakikat manusia, paham individualisme, naturalisme, komunikasi, tradisi, budaya termasuk nilai religius.

Arsitektur Simbolis: Arsitektur Simbolis adalah sebuah perihal pemakaian simbol atau lambang untuk mengekspresikan ide-ide secara arsitektural yang akan dapat diperlihatkan melalui jati diri suatu karya arsitektur sekaligus mempunyai makna dan nilai-nilai simbolik yang dapat dihasilkan melalui bentuk, struktur dan langgam. Simbolis yang dipakai dalam tema kali ini adalah Intangible Metaphors (metafora yang tidak diraba/tersamar) yang termasuk dalam kategori ini misalnya suatu konsep, sebuah ide, kondisi manusia atau kualitas-kualitas khusus (individual, simbol, naturalistis, komunitas, tradisi dan budaya).

Untuk standart-standart ruang yang pertama menggunakan buku Arsitek Data. (Neuvert, 1999). Dan untuk standart-standart ruang yang kedua menggunakan buku Time Saver Standart. (De Chiara \& Callender, 1980).

Perencanaan dan Perancangan Pengembangan Komplek Museum Purbakala Trinil di Kabupaten Ngawi adalah area / tempat yang membentuk suatu gabungan bangunan yang menyimpan peninggalan sejarah zaman purbakala, yang nantinya akan dipamerkan dan dijadikan tempat penelitian benda-benda peninggalan zaman purba. Dimana nantinya area tersebut akan dikembangkan pada pemaksimalan dan penambahan fasilitas sesuai dengan kebutuhan yang diperlukan tempat tersebut agar berjalan secara maksimal. Tempat tersebut berada pada situs Trinil di Kabupaten Ngawi.

\section{Metode Penelitian}

Metode yang digunakan dalam penelitian adalah Metode Deskriptif. Sumber data yang diperoleh adalah Data Primer adalah Observasi Lapangan dan Wawancara (Museum Majapahit Trowulan Mojokerto, Museum Mpu Tantular Sidoarjo dan Museum 10 Nopember Surabaya). Data Sekunder: Literatur, Web dan Buku.

\section{Analisa Ruang}

Rencana pengembangan fasilitas di bagi menjadi 2 bagian yaitu fasilitas utama dan fasilitas penunjang. Rencana pada fasilitas utama terdiri dari Gedung Edukasi \& Pameran 1, Gedung Pameran 2 \& Arkeolog, Restoran \& Kafe. Rencana pada fasilitas penunjang terdiri dari Pendopo, Gedung Pengelola, Asrama, Gedung Pertemuan, Area Outbond, Klinik Kesehatan \& Musholla, Gedung Utilitas \& Gudang Penyimpanan Utama. (Neuvert, 1999).

Tabel 1. Rencana Pengembangan Fasilitas

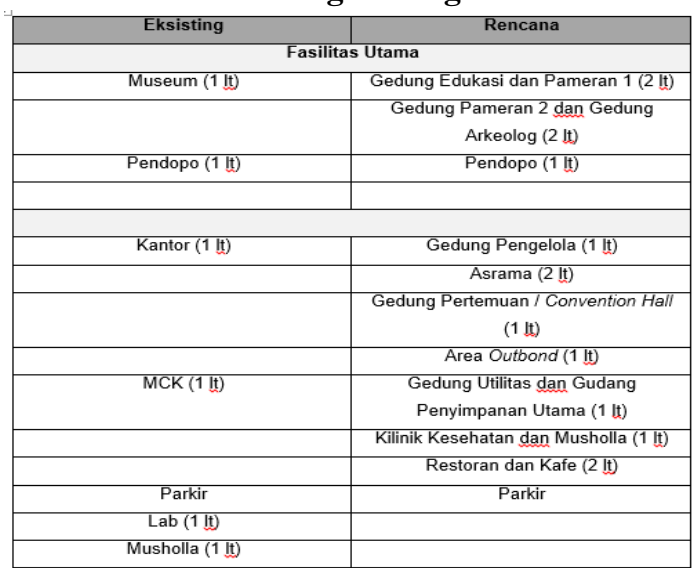

Sumber: data pribadi. 
Setelah merencanakan pengembangan fasilitas maka dihitunglah kebutuhan ruang dan diperolehlah hasil perhitungan akhir sebagai berikut.

\section{Tabel 2. Total Luasan}

\begin{tabular}{|c|c|}
\hline FASILITAS & LUASAN \\
\hline Fasilitas Utama & $2584,25 \mathrm{M} 2$ \\
\hline Fasilitas Penunjang & $6627,24 \mathrm{M} 2$ \\
\hline Sirkulasi Kendaran dan Manusia $\mathbf{4 0} \%$ & $12.896,08 \mathrm{M} 2$ \\
\hline Taman 20\% & $2.579,21 \mathrm{M} 2$ \\
\hline TOTAL KESELURUHAN & $15.475,30 \mathrm{M} 2 / 1,54 \mathrm{Ha}$ \\
\hline
\end{tabular}

Sumber: data pribadi.

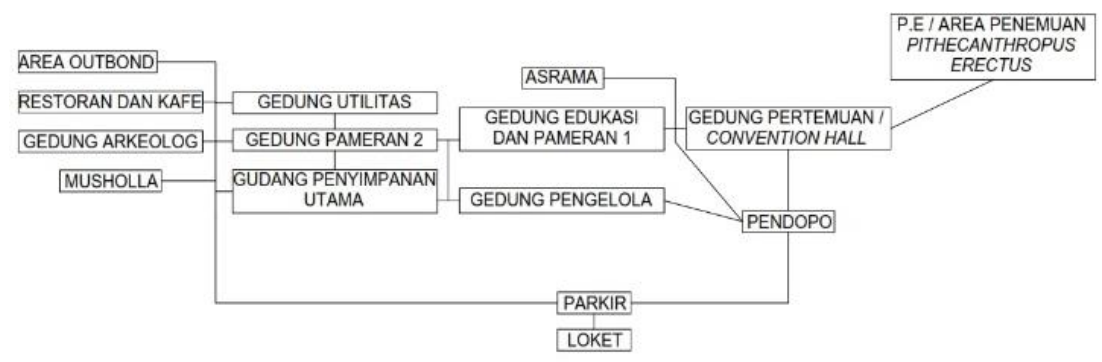

Gambar 1. Organisasi Fasilitas

Sumber: data pribadi.

\section{Zonifikasi Fasilitas:}

Publik: Parkiran, Restoran dan Kafe, Outbond, Gedung Pameran 1 dan Edukasi, Gedung Pameran 2 dan Arkeolog. Transisi: Pendopo, Gedung Pengelola, Convention Hall dan Klinik Kesehatan dan Musholla.Privat: Asrama, Gedung Utilitas, Gudang Penyimpanan Utama. (De Chiara \& Callender, 1980)

\section{Analisa Lahan}

\section{Aksesbilitas Pada Lahan / Site}

Berlokasi 1,5 km dari JL. Nasional Ngawi-Solo. 4 km dari SPBU Watualang. $10 \mathrm{~km}$ dari AlunAlun Kota Ngawi. 8 km dari Terminal Kertonegoro. 3 km SPBU Sidowayah. 2 km Restoran. Besar Transit Bus Jurusan Jogja RM. Duta. $10 \mathrm{~km}$ Stasiun Kedunggalar. Berdasarkan Peraturan Daerah Kabupaten Ngawi nomor 4 tahun 2006, berikut Kebijakan yang tertera pada peraturan tersebut: KDB: 50\%, KLB: 20\%, GSB: 25\% Lebar jalan, GSP: 5\% Lebar Jalan, RTH: $20 \%$.
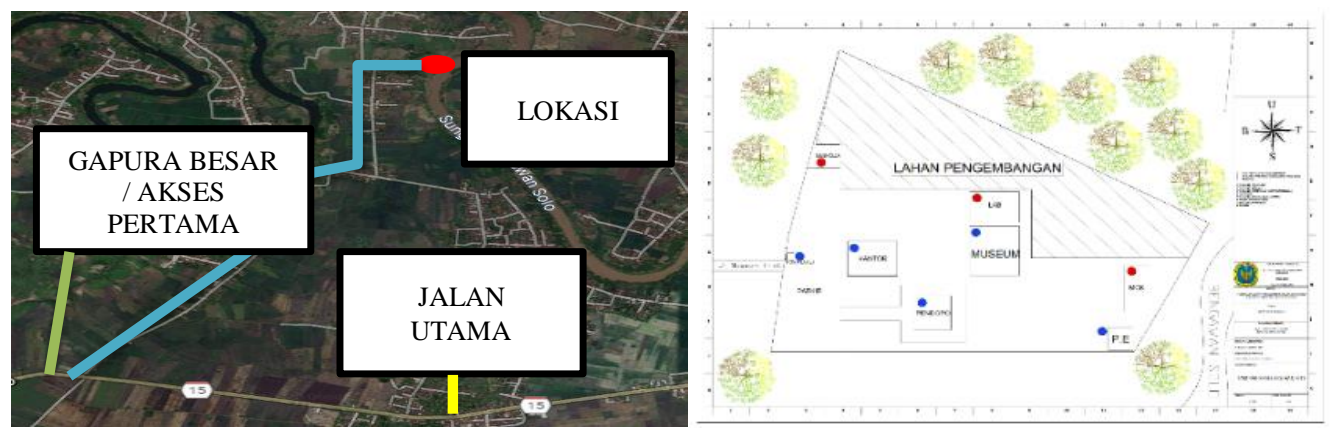

Gambar 2. Aksesbilitas Lokasi Museum Trinil (kiri) dan Denah Eksisting (kanan) Sumber: data pribadi 


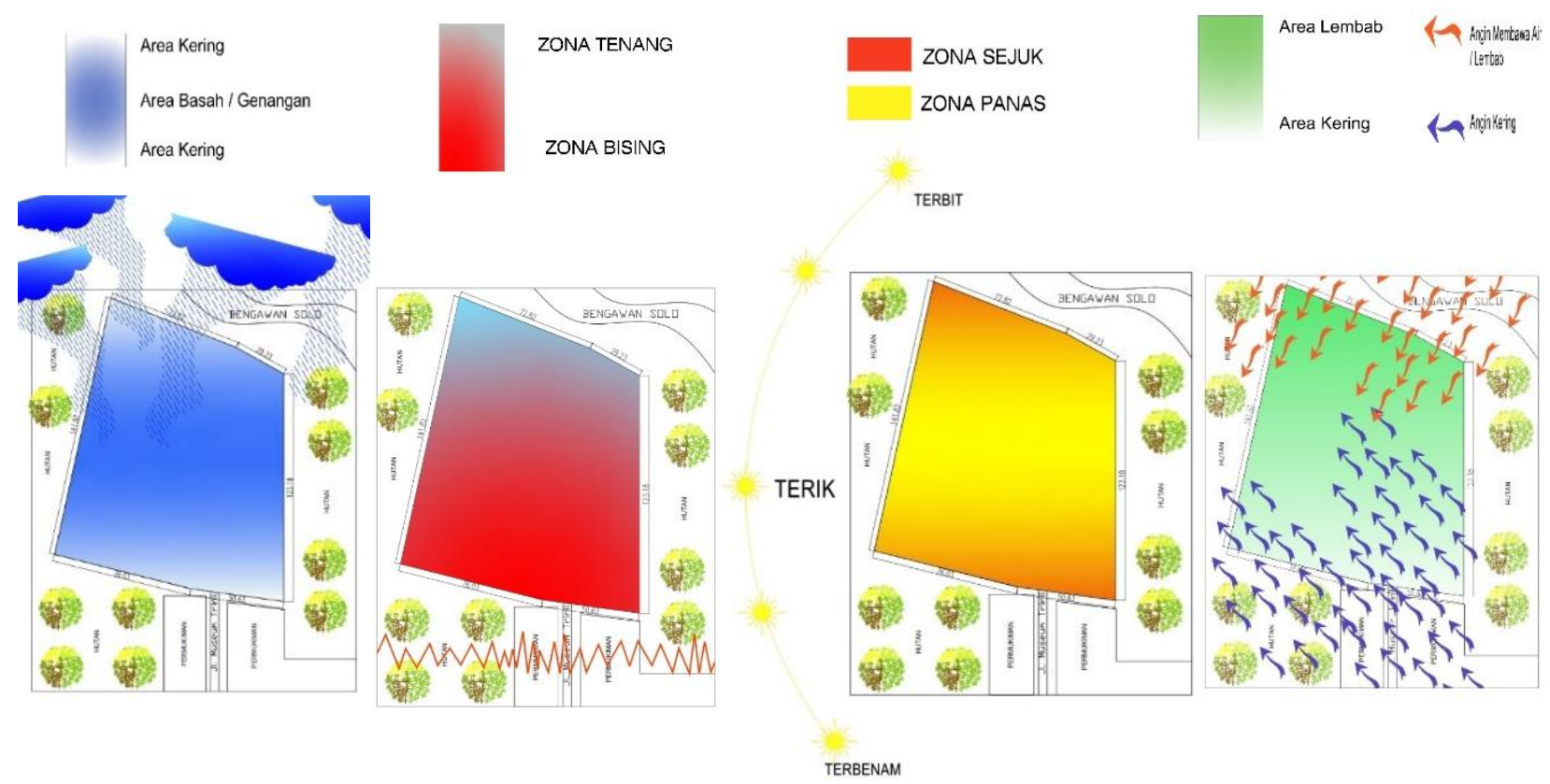

Gambar 3. Analisan Site

Sumber: data pribadi.

\section{Sintesis Tapak Secara Umum}

(a) Tapak berada pada area pemukiman dan Bengawan Solo. (b) Analisa di atas (Klimatogi matahari, hujan, angin dan kebisingan harus direspon dengan cara memberikan solusi pada desain misal, untuk mengurangi kebisingan maka di tambahkan vegetasi agar dapat di filter, untuk hujan maka disediakan saluran kawasan dan tampungan agar keluar pada saluran akhir (bengawan solo) dalam keadaan layak buang.

\section{Sintesis Tapak Berkaitan Dengan Tema}

(a) Untuk vegetasi pembatas (barier) didominasi menggunakan tanaman bambu dikarenakan bambu adalah ciri khas dari nama Kabupaten Ngawi, yang berasal dari bahasa sansekerta "AWI" memiliki arti bambu. (b) Pada penataan massa nantinya perletakan pendopo selalu diletakkan pada bagian depan sesuai dengan adat setempat. (c) Penataan sirkulasi pada area wahana akan dibuat spiral menyatu dengan bentuk bengawan.

\section{Pembahasan}

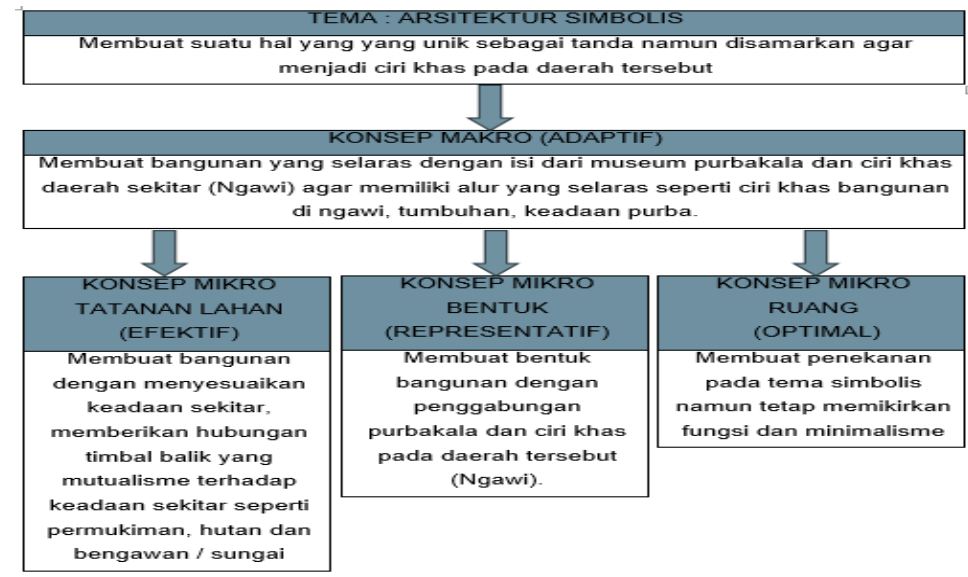

Gambar 4. Konsep Rancangan

Sumber: data pribadi. 
Tatanan Lahan menggunakan konsep mikro "Efektif" dimana untuk penataan masa bangunan, penataan parkir dan penataan sirkulasi nantinya harus memudahkan pengguna fasilitas dan juga berkesinambungan dengan keadaan eksisting.

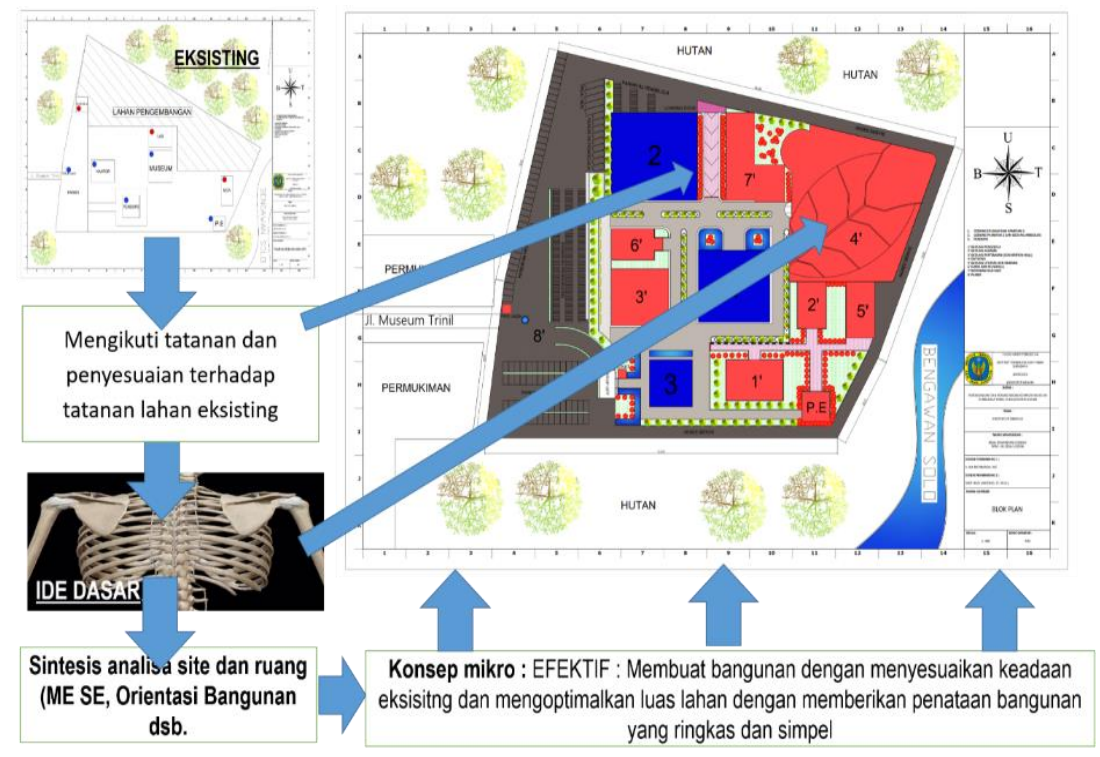

Gambar 5. Transformasi Tatanan Lahan

Sumber: data pribadi

Studi Banding Lapangan mengambil obyek: (a) Museum Majapahit Trowulan Mojokerto (kajian obyek). (b) Museum Mpu Tantular Sidoarjo (kajian obyek). (c) Museum 10 Nopember Surabaya (kajian tema).
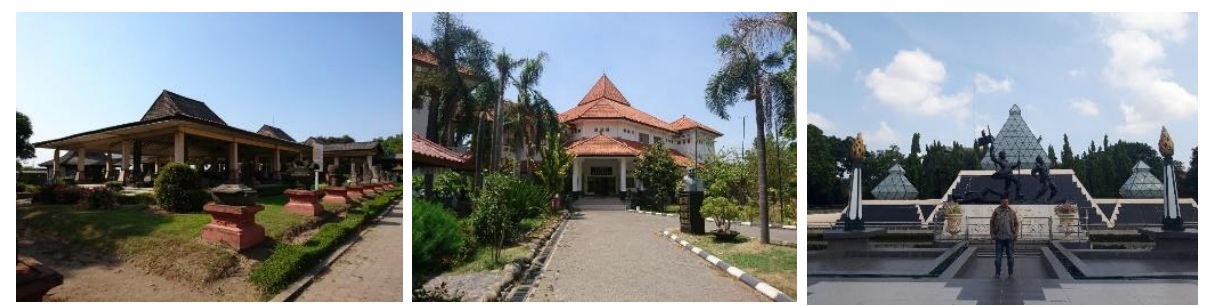

Gambar 5. (kiri) Museum Majapahit Trowulan Mojokerto; (tengah) Museum Mpu Tantular Sidoarjo; dan (kanan) Museum 10 Nopember Surabaya

Sumber: data pribadi

Studi Banding Literatur mengambil obyek: (a) Museum Tsunami Aceh (kajian obyek). (b) Masjid Raya Minang Sumatra Barat (kajian tema).
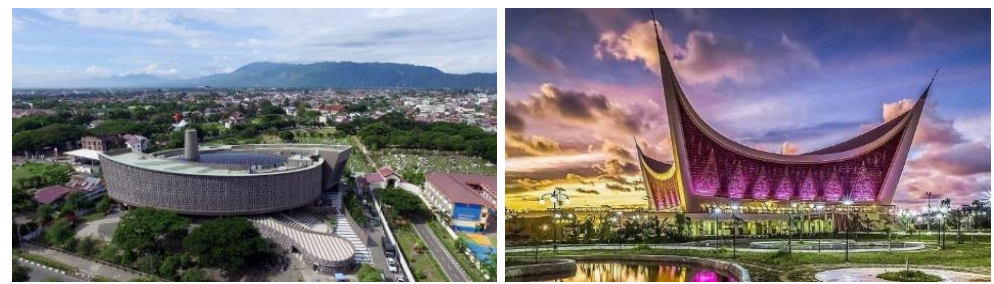

Gambar 6. (kiri) Museum Tsunami Aceh; dan (kanan Masjid Raya Minang Sumatra Barat Sumber: data pribadi 
Tabel 3. Proses Terjadinya Konsep Mikro Bentuk

\begin{tabular}{|c|c|c|c|c|}
\hline ASPEK & ANALISIS & RESPON & $\begin{array}{l}\text { SUB MIKRO } \\
\text { KONSEP }\end{array}$ & $\begin{array}{l}\text { MIKRO } \\
\text { KONSEP }\end{array}$ \\
\hline $\begin{array}{l}\text { TAMPILAN } \\
\text { BANGUNAN }\end{array}$ & $\begin{array}{l}\text { Beberapa bangunan belum memiliki } \\
\text { tampilan khas nya sesuai dengan daerah } \\
\text { nya }\end{array}$ & $\begin{array}{l}\text { Membuat tampilan bangunan } \\
\text { yang nantinya dijadikan } \\
\text { ikonik pada daerah setempat }\end{array}$ & Representatif & \multirow[t]{4}{*}{ Representatif } \\
\hline $\begin{array}{c}\text { KEPALA } \\
\text { BANGUNAN }\end{array}$ & $\begin{array}{l}\text { Pada kepala bangunan rata-rata memiliki } \\
\text { bentuk ciri khas daerah setempat }\end{array}$ & $\begin{array}{l}\text { Membuat bentuk khas yang } \\
\text { terdapat pada dearah setempat }\end{array}$ & Representaif & \\
\hline $\begin{array}{c}\text { BADAN } \\
\text { BANGUNAN }\end{array}$ & $\begin{array}{l}\text { Pada bagian badan bangunan nampak } \\
\text { monoton dimana kebanyakan yang ada } \\
\text { adalah dinding biasa yang lurus tanpa } \\
\text { aksen yang kuat }\end{array}$ & $\begin{array}{l}\text { Memberikan aksen dan } \\
\text { simbol daerah Ngawi dan isi } \\
\text { museum purbakala }\end{array}$ & Representatif & \\
\hline $\begin{array}{c}\text { KAKI } \\
\text { BANGUNAN }\end{array}$ & $\begin{array}{l}\text { Kaki bangunan seperti ciri rumah adat } \\
\text { jawa yang nampak lebih melebar (umpak) }\end{array}$ & $\begin{array}{l}\text { Membuat pelebaran bidang } \\
\text { pada bagian kaki bangunan }\end{array}$ & Representatif & \\
\hline
\end{tabular}

Sumber: data pribadi

Bentuk menggunakan konsep mikro "Representatif" dimana pembuatan bentuk bangunan dengan penggabungan unsur kepurbakalaan dan ciri khas pada daerah tersebut (Ngawi).

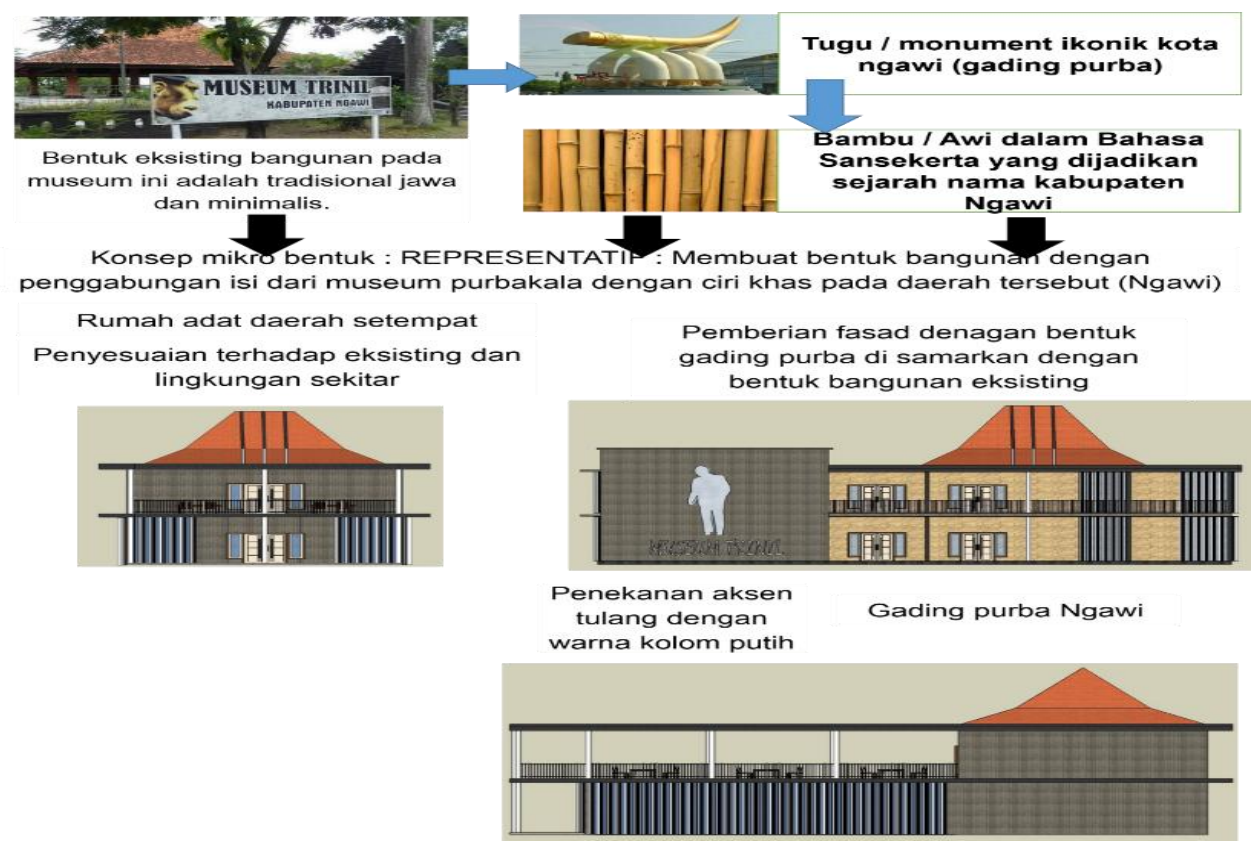

Gambar 7. Transformasi Bentuk

Sumber: data pribadi

Ruang menggunakan konsep mikro "Optimal" dimana dalam membuat penekanan pada tema Arsitektur Simbolis tetap memikirkan fungsi dan minimalisme. 


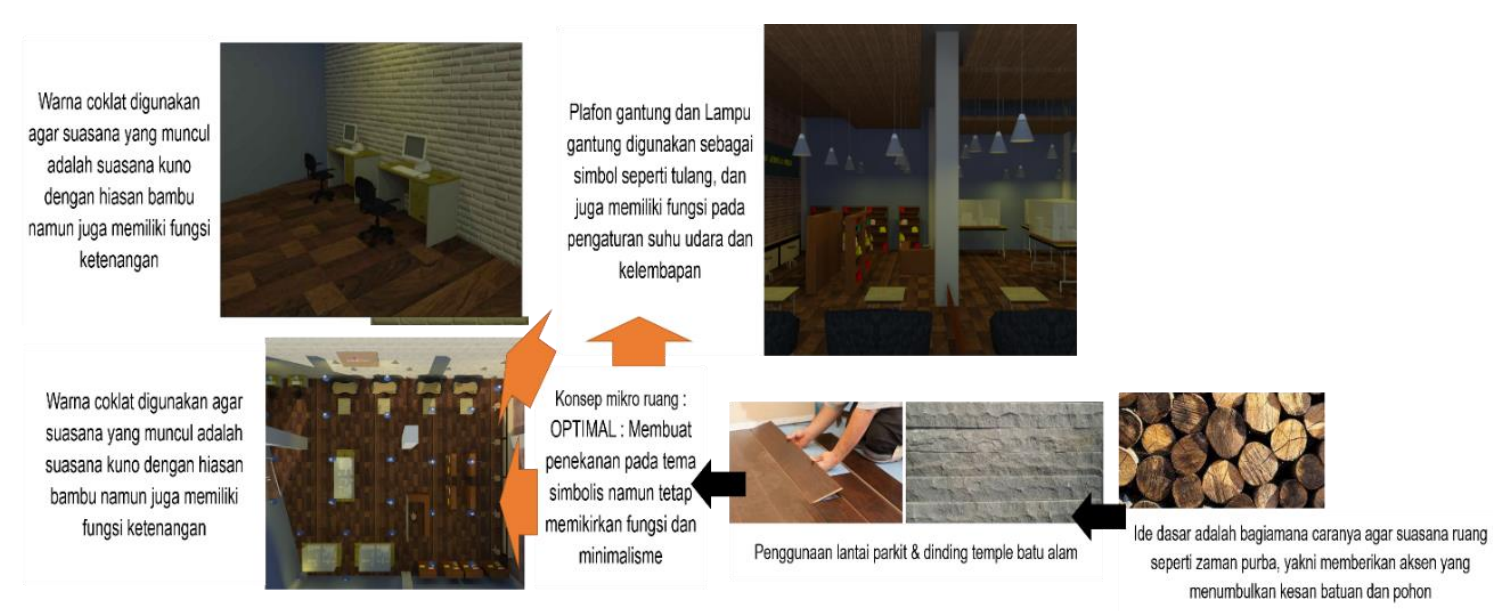

Gambar 8. Transformasi ruang

Sumber: data pribadi

\section{Kesimpulan}

Tema yang digunakan untuk rancangan ini adalah simbolis, simbolis disini menggunakan metafora tersamar dimana perwujudannya dengan cara disamarkan agar orang yang melihat obyek tersebut berfikir dan memiliki sudut pandang masing-masing, dimana prosesnya dengan cara adapatasi/ menyatu dengan lingkungan sekitar dan mengambil bentuk-bentuk yang menjadi ciri khas daerah Ngawi dengan penekanan aksen purbakala. Penerapan tema pada tatanana lahan adalah bentuk sirkulasi seperti tulang, penerapan tema pada bentuk adalah pada atap menggunakan atap yang terdapat pada daerah tersebut dengan ditambah bentuk dan tekstur purba seperti bebatuan dan tulang, penerapan tema pada ruang adalah penekanan aksen bebatuan dan warna batu dan kayu. Konsep makro pada objek tersebut adalah adaptif dimana membuat desain museum purbakala dengan menggabungkan ciri khas daerah Ngawi. Penerapan konsep makro adaptif pada tatanan lahan yaitu sirkulasi dan penataan masa mempertimbangkan eksisting, penerapan konsep makro adaptif pada bentuk adalah pengabungan unsur lokal dan penekanan unsur purbakala. penerapan konsep makro adaptif pada ruang adalah penyesuaian dan penekanan unsur purbakala. Mikro konsep pada tatanan lahan yaitu efektif, penerapannya memaksimalan sirkulasi eksisting agar lebih baik, bentuk yaitu representatif, penerapannya dengan menggabungan bentuk budaya dan unsur kepurbakalaan dan ruang yaitu efektif, penerapannya menampilkan penekanan unsur kepurbakalaan namun tetap memikirkan efisiensi ruang. Manfaat dari perancangan objek ini yaitu agar Museum Trinil berjalan lebih maksimal lagi, memberikan wadah untuk penelitian dan orang yang ingin belajar ilmu kepurbaan dan menjadikan suatu ikon yang besar untuk Kabupaten Ngawi.

\section{Referensi}

Asy'ari, A. H., M., \& Nirwansyah, R. (2013). Metafora Akselerasi Dalam Objek Rancang Sirkuit Balap Drag Nasional. Jurnal Sains dan Seni ITS, 2(2), G-138-G-141.

Arrumaisa, N., \& Suryawan, W. A. (2014). Pendekatan Rancang Metafora dalam Perancangan Kafe dan Karaoke. Jurnal Sains Dan Seni POMITS, 3(2), 57-59. https://ejurnal.its.ac.id/index.php/sains_seni/article/download/6724/2054

De Chiara, J., \& Callender, J. (1980). Time-Saver Standards for Building Types. In McGraw-Hill;

Neuvert, E. (1999). Data Arsitek Jilid 2 Edisi 33. Erlangga, Jakarta.

Prihutama, M., \& Ashadi. (2020). Kajian Konsep Arsitektur Metafora pada Bangunan Bertingkat Tinggi. Jurnal Arsitektur Zonasi, 3(2), 220-232. https://doi.org/doi.org/10.17509/jaz.v3i2.25057

Shauma Eska Pranata, Amanati, R., \& Firzal, Y. (2017). Mall di Kota Dumai gengan Pendekatan Arsitektur Postmodern Metafora. Jurnal Online Mahasiswa (JOM) Bidang Teknik Dan Sains, 4(2). https://jom.unri.ac.id/index.php/JOMFTEKNIK/article/download/16903/16320 